
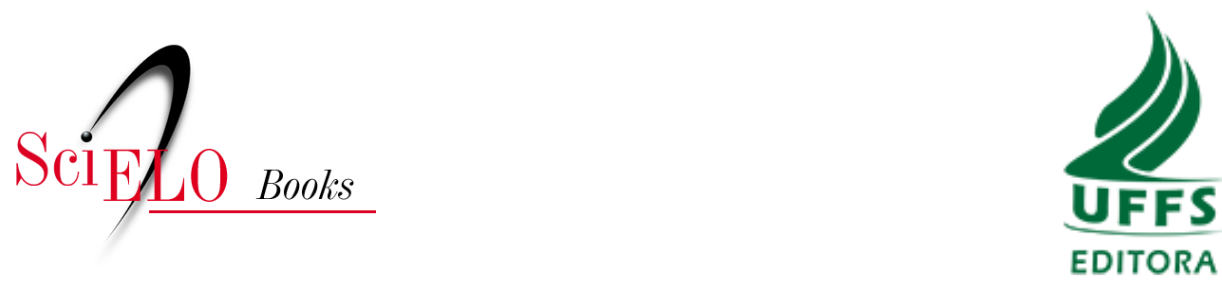

\title{
Parte VII - Desenvolvimento e políticas públicas Capítulo 5 - Aspectos teóricos e a prática do desenvolvimento no Brasil: o estado e as políticas públicas como instrumentos da reprodução do capital
}

\author{
Edemar Rotta
}

Carlos Nelson dos Reis

\section{SciELO Books / SciELO Livros / SciELO Libros}

ROTTA, E., and REIS, C.N. Aspectos teóricos e a prática do desenvolvimento no Brasil: o estado e as políticas públicas como instrumentos da reprodução do capital. In: ROTTA, E., LAGO, I.C., JUSTEN, A.F., and SANTOS, M., eds. Conhecimento em rede:

desenvolvimento, cooperação e integração regional em território de fronteira - Rede CIDIR: 10 anos [online]. Chapecó, SC: Editora UFFS, 2019, pp. 504-522. ISBN: 978-65-5019-011-8. https://doi.org/10.7476/9786586545432.0030.

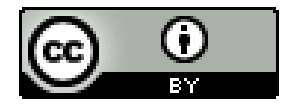

All the contents of this work, except where otherwise noted, is licensed under a Creative Commons Attribution 4.0 International license.

Todo o conteúdo deste trabalho, exceto quando houver ressalva, é publicado sob a licença Creative Commons Atribição 4.0. 


\section{ASPECTOS TEÓRICOS E A PRÁTICA DO DESENVOLVIMENTO NO BRASIL: O ESTADO E AS POLÍTICAS PÚBLICAS COMO INSTRUMENTOS DA REPRODUÇÃO DO CAPITAL}

Edemar Rotta ${ }^{1}$

Carlos Nelson dos Reis ${ }^{2}$

\section{INTRODUÇÃO}

O processo de reestruturação capitalista, realizado a partir das últimas décadas do século XX, sob a hegemonia do referencial teórico neoliberal, intensificou a disputa pelo controle dos diferentes espaços de influência sobre o

1 Doutor em Serviço Social (PUCRS). Mestre em Sociologia (UFRGS). Professor da UFFS. Em estágio de Pós-Doutoramento no Programa de Pós-Graduação em Serviço Social (PUCRS). Contato: erotta@ uffs.edu.br

2 Pós-Doutorado na Universidade de Paris 13 Nord. Doutor em Política Econômica (UNICAMP). Mestre em Teoria Econômica (UFRGS). Contato: cnelson@pucrs.br 
processo de reprodução do capital, entre os quais se pode situar o Estado e, no seu contexto, as políticas públicas. As forças ligadas ao capital produzem uma ideologia de culpabilização do Estado Social, exigindo sua redefinição na direção do "Estado mínimo". Porém, ao referir o mercado como o lócus de referência para a definição de todas as relações econômicas e sociais, a proposta neoliberal sinaliza, portanto, advogar um "Estado máximo" para o capital e um "Estado mínimo" para o social (NETTO, 2012). Ou seja, um Estado que restrinja suas ações na área das políticas públicas sociais em nome do "ajuste fiscal" e da redução de seu "peso" sobre a estrutura econômica, mas que continue forte para garantir as estratégias de valorização do capital.

Entende-se o Estado como uma condensação de relações sociais, perpassado pelo conjunto das relações de classe presentes na formação histórica concreta (GRAMSCI, 1968). O Estado incorpora e responde aos conflitos presentes na dinâmica das relações que os indivíduos estabelecem entre si no processo de produção e reprodução social. O Estado não é uma entidade autônoma, atemporal, acima e além do embate entre as forças sociais, como apregoam os liberais. Também não é apenas objeto privilegiado da dominação dos interesses de uma classe ou fração de classe sobre as demais, atuando como um "comitê executivo da burguesia", como apregoam os marxistas mais ortodoxos e reducionistas (MENDONÇA, 2007). O Estado é "um aparato jurídico-político cuja organização e intervenção varia de acordo com a organização social, política, econômica e cultural da sociedade, mediadas pelas correlações de forças entre as frações de classes vigentes" (SILVA, 2015, p. 10).

Em sociedades e estados complexos, como os predominantes no cenário atual, o processo de definição das políticas públicas tende a ser perpassado pela multiplicidade de interesses e contextos históricos concretos, tanto em nível interno quanto externo. O Estado possui "uma autonomia relativa", "um espaço próprio de atuação", porém permeável a estas influências internas e externas (SOUZA, 2006).

É nessa perspectiva de dinâmica de relações que se propõe a análise de dois momentos específicos da história brasileira nos quais se constituem como hegemônicas propostas desenvolvimentistas: o período 1930-1970, tido como o nascimento e a implantação do desenvolvimentismo; e o período que se dá a partir da primeira década do século XXI, quando um governo de centro-esquerda 
conquista a Presidência da República e se mantém no poder por mais de três mandatos consecutivos (13 anos e meio), implantando o que parte da literatura tem denominado de "novo-desenvolvimentismo".

Estrutura-se esta reflexão da seguinte maneira: no primeiro tópico trata-se o desenvolvimentismo, em suas bases teóricas e seus projetos concretos de governo, centrando a análise no Plano de Metas, tido como ápice deste "modelo". No segundo, caracteriza-se a retomada do desenvolvimentismo, a partir da crise das formulações fundadas no ideário neoliberal e a emergência do "novo-desenvolvimentismo" e do "social-desenvolvimentismo", com acento especial no Programa de Aceleração do Crescimento (PAC).

\section{O DESENVOLVIMENTISMO CLÁSSICO E O PLANO DE METAS}

Os primórdios da experiência desenvolvimentista brasileira podem ser encontrados nas primeiras décadas do século XX, em especial a partir da "Revolução de 1930". Porém, é consenso entre os pesquisadores da área que ela se efetiva, de forma mais estruturada, na década de 1950, encontrando seu apogeu com o Programa de Metas (mais conhecido como Plano de Metas), atravessando momentos de oscilações ao longo das décadas de 1960 e 1970, para enfrentar sua crise mais profunda na década de 1980 (BIELSCHOWSKY, 2011; CARNEIRO, 2012; FONSECA, 2014).

A proposta desenvolvimentista nasce em um contexto de crise do modelo agrário exportador, hegemônico no Brasil desde a sua independência. A crise esteve relacionada às transformações do cenário internacional ( $1^{\circ}$ Guerra Mundial, crise de 1929, crise das propostas liberais, emergência do socialismo, entre outras) e nacional (crise econômica, emergência dos movimentos sociais e culturais, crise política, desigualdades regionais, crescimento das cidades, entre outras), que evidenciaram a situação de "atraso estrutural" em que o país se encontrava e para a qual precisava buscar alternativas (ROTTA, 2007).

A "Revolução de 1930" representou, de certa forma, a construção de uma nova hegemonia, assentada na aliança entre a incipiente burguesia industrial, as camadas médias urbanas e as elites rurais descontentes com a tradicional política 
do "café com leite"3. Esse novo arranjo hegemônico que passou a ser constituído encontrou no ideário positivista um de seus pilares básicos de estruturação e sustentação. O positivismo era uma versão capitalista aceitável para as elites locais, pois seu projeto de "modernidade e reforma social" efetivava uma mudança econômica e cultural, sem grandes alterações na estrutura de classes e de poder presentes no Brasil (ROTTA, 2007); trazia a compreensão do futuro construído, a partir de etapas progressivas, que podem ser aceleradas pela ação intervencionista do Estado, no sentido de enfrentar e superar as barreiras que se antepõem ao progresso; e afirmava a centralidade da política, precedendo a economia, como o espaço por excelência da ação humana capaz de alterar o curso da história (FONSECA, 2014).

Além do ideário positivista, os articuladores do desenvolvimentismo nascente incorporaram as contribuições dos "nacionalistas" - defesa do mercado interno, do protecionismo, do capital nacional e da industrialização, dos "papelistas" - no que concerne a admitir o crédito, o déficit público e os empréstimos como indispensáveis para alavancar a economia, e dos defensores da indústria - no que concerne à criação de incentivos, inclusive tarifários e fiscais, porém sem prejudicar a relação com o mercado comprador e fornecedor, considerados indispensáveis ao desenvolvimento da indústria nacional (FONSECA, 2014).

Esse "arranjo" ideológico e de interesses permitiu: estabelecer uma política de proteção à indústria nacional contra a concorrência externa; mobilizar recursos que o empresariado nacional não possuía para criar uma infraestrutura adequada ao desenvolvimento industrial; apoiar a expansão do setor privado, através de subsídios creditícios e incentivos fiscais; criar uma legislação trabalhista e previdenciária que atraísse mão de obra do meio rural para os centros urbanos; reordenar a estrutura agrária, incentivando a produção de alimentos a baixos custos para os trabalhadores urbanos e buscando novas inserções no mercado externo; mobilizar o país em torno de "um projeto de Nação" que superasse as desigualdades regionais; realizar uma série de investimentos na indústria de base, fundamental para a alavancagem de um processo efetivo de industrialização; ampliar a diversificação econômica; desenvolver os meios de transporte; incorporar gradativamente o proletariado à sociedade; fortalecer

3 Acordo estabelecido entre as oligarquias paulista e mineira no sentido de viabilizar a alternância entre elas na definição e apoio de candidatos para o cargo de Presidente do país durante a República Velha. 
uma camada média de proprietários imbuídos de um sentimento patriótico de amor ao trabalho e de respeito às leis estabelecidas; introduzir novas técnicas capazes de aumentar a produtividade do trabalho. Para implantar essa política, utilizavam-se estratégias que alternavam coerção, consenso e "autonomia controlada", marcas da "Era Vargas" (ROTTA, 2007).

A "Era Vargas" estabeleceu as bases iniciais de construção da proposta desenvolvimentista que se consolidou com o governo Juscelino Kubitscheck de Oliveira (JK, 1956-61). Beneficiando-se da estrutura já constituída em termos de administração pública, assim como de ambiente político favorável à consolidação de propostas desenvolvimentistas, JK propõe substituir o "nacionalismo getulista" pelo "desenvolvimentismo" (CARDOSO, 1977). Com a proposta dos "Cinquenta anos em Cinco" e o "Plano de Metas, "o pensamento sobre a transformação se tornou hegemônico em relação ao pensamento sobre a conjuntura" (BIELSCHOWSKY, 2011, p. 19). A aliança entre o Estado, a iniciativa privada, o capital internacional, as forças militares, as elites agrárias e os trabalhadores constituíam ampla base de sustentação, que permitia levar adiante a proposta (ROTTA, 2007).

O núcleo central da proposta de desenvolvimento apresentada por Juscelino foi o Programa de Metas, ou "Plano de Metas", como ficou conhecido. Um plano alicerçado em 30 metas $^{4}$ e mais uma tida como "meta síntese", que foi a construção de Brasília e transferência da capital federal. A elaboração do Plano esteve sob a responsabilidade de uma equipe, coordenada pelo engenheiro Lucas Lopes (nomeado Ministro da Fazenda em 1958) e pelo economista Roberto Campos (Superintendente do BNDE), que aproveitaram experiências anteriores de planejamento e de diagnósticos da situação socioeconômica do país, tais como a Missão Cooke, a Missão Abbink, a Comissão Mista Brasil-Estados Unidos (CMBEU), o Grupo Misto BNDE-CEPAL, o Plano SALTE, entre outras (DIAS, 1996; LAFER, 2002). O plano visava superar os pontos de "estrangulamento interno e externo" que dificultavam o processo de desenvolvimento do país, via industrialização (LAFER, 2002).

O Plano de Metas foi estruturado a partir de cinco áreas fundamentais: energia, transportes, alimentação, indústrias de base e educação. Para cada área definiu-se um conjunto de metas, que se desdobravam em projetos específicos,

4 Descrição detalhada das metas pode ser encontrada em Dias (1996) e Lafer (2002). 
a serem executados pela integração de ações entre o Estado (em suas diferentes esferas e através das empresas e instituições públicas) e a iniciativa privada (nacional e internacional). A área de energia (elétrica, nuclear, carvão mineral, produção e refino de petróleo) foi a que mobilizou o maior contingente $(43,4 \%)$ de recursos previstos, pois foi identificada como o maior estrangulamento existente no país para o desenvolvimento da indústria. Na sequência vem a área de transportes (reaparelhamento ferroviário, construção de ferrovias e de rodovias, pavimentação de rodovias, serviços portuários e de dragagem, marinha mercante e transporte aéreo), com previsão de 29,6\% dos investimentos, e as indústrias de base (siderúrgica, alumínio, cimento, álcalis, papel e celulose, borracha, metais não ferrosos, construção naval, automóveis, mecânica, material elétrico e exportação de minério de ferro), com $20,4 \%$ dos investimentos previstos. Nessas três áreas concentravam-se 93,4\% dos recursos a serem aplicados, em 23 metas, dando a dimensão de uma proposta centrada na dimensão econômica e respondendo, predominantemente, aos interesses do capital industrial (BRASIL, 1958; DIAS, 1996).

As metas (seis no total) para a área de alimentação (produção de trigo, silos e armazéns, matadouros e frigoríficos, mecanização da agricultura e fertilizantes) previam a aplicação de 3,2\% dos recursos, amplamente dominadas por projetos de cunho nitidamente econômico e voltados para o processo de modernização da agricultura e aumento da capacidade de produção e armazenamento. A meta voltada para a educação (formação de pessoal técnico e orientação da Educação para o Desenvolvimento) previa a aplicação de 3,4\% dos recursos projetados, concentrando-se em projetos de atuação do Estado nos três níveis de educação: primário, médio e superior. Entre as ações, destacam-se a expansão da oferta do ensino primário, a criação de classes especiais, a extensão do ano letivo, a construção e o reaparelhamento de escolas, a qualificação dos professores, a aquisição de equipamentos, a realização de cursos técnicos, a concessão de bolsas de estudo para alunos de nível médio em cursos profissionalizantes, a ampliação da oferta de cursos de engenharia, a instituição do regime de tempo integral dos professores, a criação de cursos de pós-graduação e aperfeiçoamento, a reforma do ensino superior e a criação de 14 Institutos de Pesquisas, Ensino e Desenvolvimento nos principais centros do país, voltados para os setores de química, 
economia, tecnologia rural, mecânica, eletro técnica, mineração, metalurgia, mecânica agrícola, matemática, física e geologia (BRASIL, 1958; DIAS, 1996).

A meta-síntese, além das trinta referidas no Plano, era a construção de Brasília e a transferência da capital federal. Meta que envolveu, praticamente, a mesma quantidade de recursos aplicada no conjunto das outras trinta, em torno de 300 bilhões de cruzeiros ${ }^{5}$, para valores de 1961. Em regra, Brasília representou uma dimensão simbólica e outra ideológica, de síntese do projeto desenvolvimentista de Juscelino (COSTA; STEINKE, 2014). Simbólica, no sentido de mobilização dos brasileiros, de todas as classes sociais e matizes ideológicas, para um projeto de futuro, capaz de desviá-los dos problemas econômicos e sociais do cotidiano e projetá-los para um cenário de modernização e desenvolvimento. Ideológica, ao trabalhar com a ideia da interiorização do poder historicamente localizado no litoral e projetá-lo para o interior do país, integrando e articulando o mercado nacional, associado ao capital estrangeiro, sob o comando econômico do setor industrial. "O governo desenvolvimentista neobismarckiano cruzou os ideais das organizações econômicas com os ideais das organizações políticas, derrubando barreiras para o controle do território e a integração essencialmente capitalística do Brasil” (COSTA; STEINKE, 2014, p. 16).

Para garantir a implantação do Plano de Metas, Juscelino tomou um conjunto de iniciativas visando superar as dificuldades políticas no Congresso e na burocracia pública. No Congresso, ele negociou uma coalizão de centro-esquerda (PSD, PTB e PSP), a partir da constituição do seu ministério, capaz de dar sustentação ao governo e garantir a aprovação de seus projetos fundamentais. Com base em um amplo consenso, com distintas origens teóricas e políticas, vai se forjar uma base política importante para o projeto desenvolvimentista, na implantação do novo padrão de acumulação de capital" (RABELO, 2003, p. 47). Em termos de administração pública, criou mecanismos e estratégias visando assegurar o funcionamento das empresas estatais e constituiu uma estrutura de administração capaz de dar agilidade e integração nas decisões e medidas tomadas. "Nesta nova institucionalidade, a execução do Plano de Metas teria como

5 Não existe unanimidade na descrição dos recursos previstos para a realização do Plano de Metas, mas os valores não são dissonantes, girando em torno de 285 a 310 bilhões de cruzeiros, em 1956. Destes, em torno de $21 \%$ proveniente de investimentos estrangeiros. Em valores atualizados para 30 de abril de 2017 teríamos a cifra de R\$ 146,6 bilhões (BRASIL, 1958; DIAS, 1996; LAFER, 2002). 
núcleo básico do mecanismo planejador e gerencial a associação concretizada entre o BNDE e o Conselho de Desenvolvimento"6 (DIAS, 1996, p. 36).

Nas análises dos resultados obtidos pelo Plano de Metas, é consenso entre os diversos ${ }^{7}$ autores que ele apresentou resultados amplamente positivos na maioria absoluta das metas. Inclusive, em muitas delas, para além do projetado. "Na sua grande maioria, naquilo que o Plano de Metas ensejava a transição da economia para o capitalismo industrial "maduro", as metas obtiveram um sucesso importante" (RABELO, 2003, p. 50). Através da ação direta e/ou indireta do Estado e da sua articulação com o capital nacional e internacional, criou-se a infraestrutura econômica indispensável para a implantação e o fortalecimento da indústria em seus mais variados ramos. Porém, o plano não se restringe às questões de infraestrutura, mas avança para a produção de bens intermediários e até mesmo de capital, ampliando o já existente ou criando novas capacidades de produção. O Plano de Metas e o conjunto de medidas adotadas pelo governo JK para implantá-lo transformam o Estado em um "eficiente instrumento de reforço da acumulação de capital e de realização da transição para um novo padrão de acumulação" (RABELO, 2003, p. 52).

Tem-se claro também que o Plano se manteve regido por uma lógica setorial de planejamento e, por mais que apresentasse ações articuladas e intercomplementares entre alguns setores, não conseguiu avançar para um planejamento global de desenvolvimento no longo prazo. Metas direcionadas para a agropecuária estão pouco presentes (apenas algumas na área de alimentação) no Plano, ainda mais considerando-se o peso desse setor na composição do Produto Interno Bruto do país neste período. O Plano também subestimou a importância das áreas de alimentação e educação na relação com as demais, fato comprovado no montante de recursos e ações específicas previstas. As dificuldades em realizar uma ampla reforma tributária fragilizaram as condições do Estado em financiar as ações previstas, fazendo-o optar pela via da inflação, penalizando os assalariados em detrimento dos detentores do capital.

6 Detalhes sobre suas atribuições, estrutura e funcionamento podem ser buscados em Dias (1996). No âmbito do Conselho destaca-se a atuação dos grupos de trabalho e dos grupos executivos. Os primeiros, em sua maioria, criados de maneira informal e responsáveis por estudos e sugestões em áreas específicas. Os segundos criados de maneira formal pelo governo, com a finalidade de elaborar e coordenar programas setoriais.

7 Vide Dias (1996), Lessa (1982), Lafer (2002), Rabelo (2003), entre outros. 
A lógica que moveu o Plano de Metas foi coerente com os alicerces da ideologia desenvolvimentista dominante no período: que o desenvolvimento da indústria irradiaria seus efeitos para as outras áreas da economia e seria capaz de superar as desigualdades sociais e regionais; que a ação do Estado, pautada por critérios de racionalidade técnica e relativa autonomia em relação aos interesses e valores dos diferentes grupos e classes sociais, fosse capaz de formular e conduzir o projeto nacional de desenvolvimento; que os conhecimentos e as técnicas produzidas pela ciência econômica seriam suficientes para reconhecer as necessidades do desenvolvimento e os meios para atingi-lo e que os marcos da sociedade capitalista seriam adequados para a viabilização do projeto (SILVA, 2000; FONSECA, 2014).

A partir da década de 1980, com a hegemonia da teoria econômica neoclássica e da ideologia neoliberal, o projeto de industrialização é abandonado pois é julgado "desnecessário" para o crescimento econômico (BRESSER PEREIRA, 2016). Na década de 1990, "as reformas neoliberais são adotadas por todos os países da periferia do capitalismo, exceto os países do Leste Asiático e a Índia. As novas palavras de ordem passam a ser desnacionalização, privatização e desregulamentação" (BRESSER PEREIRA, 2016, p. 151). Não é objeto deste texto a análise da proposta neoliberal, uma vez que se concentra o foco no ideário desenvolvimentista. A seguir trabalha-se a retomada do desenvolvimentismo, na esteira da crise da proposta neoliberal dos anos 1980-90.

\section{O "NOVO-DESENVOLVIMENTISMO" E/OU "SOCIAL- DESENVOLVIMENTISMO”: O PAC COMO REFERÊNCIA}

A crise das formulações de políticas econômicas e sociais implantadas com base no ideário neoliberal, nas mais diversas partes do mundo, torna-se amplamente visível a partir do final da década de 1990. Aspectos dela manifestam-se no crescimento das taxas de desemprego, na ampliação das desigualdades sociais e regionais, na concentração de renda e nas baixas taxas de crescimento econômico. "A incapacidade do Consenso de Washington em fundamentar políticas econômicas capazes de engendrar processos de desenvolvimento mais duradouros" (CARNEIRO, 2012, p.767), levou a críticas recorrentes de suas 
concepções e à derrota das coalizões políticas que lhe davam sustentação, em especial na América Latina.

No caso do Brasil, a partir das críticas ao ideário neoliberal e das "novas coalizões políticas" que se formam na tentativa de construir uma nova hegemonia, emergem, de forma geral $^{8}$, duas vertentes de pensamento identificadas com o ideário desenvolvimentista: o novo-desenvolvimentismo e o social-desenvolvimentismo (CARNEIRO, 2012; FONSECA, 2014). O novo-desenvolvimentismo tem origem em grupos e intelectuais que realizam a crítica à política macroeconômica do governo Fernando Henrique Cardoso (FHC), muitos deles ligados ao pensamento liberal, tendo em Luiz Carlos Bresser Pereira seu principal representante teórico. O social-desenvolvimentismo tem origem na equipe de governo do Presidente Luís Inácio Lula da Silva, especialmente a partir do seu segundo mandato, sendo mais presente nas instâncias políticas, porém buscando afirmação na academia com as elaborações de Ricardo Bieslchowsky, Márcio Pochmann, Guido Mantega, Luciano Coutinho, Aloizio Mercadante Oliva, entre outros.

O novo-desenvolvimentismo nasce no início dos anos 2000, como uma reação ao "duplo populismo", o fiscal e o cambial, tidos como a base do fracasso, tanto dos liberais quanto dos velhos desenvolvimentistas, na tentativa de promover o crescimento com estabilidade (BRESSER PEREIRA, 2016). Essa concepção ganha corpo com a aprovação das "Dez Teses sobre o Novo-Desenvolvimentismo", em julho de 2010, afirmando-se como uma "nova escola de pensamento". Tem seu foco nos países de renda média, que já realizaram sua revolução industrial e capitalista; propõe igualdade de condições de competição para as empresas industriais, principalmente porque a taxa de câmbio tende a ser sobreapreciada no longo prazo; rejeita a tese do crescimento com poupança e endividamento externo; defende um modelo baseado na exportação de bens manufaturados apoiado em uma taxa de câmbio de equilíbrio industrial ou competitiva; propõe a integração internacional competitiva dos países em desenvolvimento, ao invés de integração subordinada (BRESSER PEREIRA, 2016).

Pode-se afirmar que a proposta novo-desenvolvimentista está calcada em quatro teses fundamentais: (1) não haverá mercado forte sem um Estado forte;

8 Há autores que trabalham com outras formulações, a exemplo de Pfeifer (2014), que trata as duas como "neodesenvolvimentistas", diferenciando autores e escolas de pensamento nesta vertente. 
(2) não haverá crescimento sustentado a taxas elevadas sem o fortalecimento dessas duas instituições (Estado e mercado) e sem a implementação de políticas macroeconômicas adequadas; (3) mercado e Estado fortes somente serão construídos por uma estratégia nacional de desenvolvimento; (4) não é possível atingir o objetivo da redução da desigualdade social sem crescimento a taxas elevadas e continuadas (SICSÚ; PAULA; MICHEL, 2007).

As origens da vertente social-desenvolvimentista são identificadas como já presentes no plano de governo da candidatura Lula, em 2002.A proposta se afirma, porém, no segundo mandato do presidente Lula, isto porque "as resistências à implementação do modelo demoraram a ser contornadas, mas também que suas bases sociais e políticas empurraram-no adiante" (BASTOS, 2012, p. 795). Foi a partir do segundo mandato (2007 a 2010) que ela se tornou hegemônica no núcleo central do governo e nas principais instituições públicas federais responsáveis pelo planejamento e pela execução das políticas públicas.

"No segundo governo Lula, houve uma conjugação de distribuição de renda e expansão do investimento" (BIELSCHOWSK, 2011, p. 21), viabilizados pelas ações do Programa de Aceleração do Crescimento (PAC) e pelos financiamentos via Banco Nacional de Desenvolvimento Econômico e Social (BNDES), Caixa Econômica Federal e Banco do Brasil. Com a expansão da capacidade de consumo, a população acessa a bens mais modernos, favorecendo a modernidade das empresas e a propagação das novas tecnologias. Cria-se um "círculo virtuoso" no qual a melhoria da distribuição de renda alimenta o investimento e o progresso técnico (BIELSCHOWSK, 2011).

A proposta social-desenvolvimentista tem seu foco central na redistribuição de renda, recuperando a tradição histórica estruturalista do desenvolvimentismo de Raúl Prebisch e Celso Furtado (FONSECA, 2014). A ideia-chave é a "definição do social como eixo do desenvolvimento" (CARNEIRO, 2012, p. 773), o que representa uma inversão de prioridade em relação ao posto pelo velho e pelo novo-desenvolvimentismo, para os quais a centralidade reside no desenvolvimento das forças produtivas. Para caracterizar o núcleo central da proposta, Carneiro recorre às contribuições de Bielschowsky (apud CARNEIRO, 2012, p. 774), em que ele afirma: "a estratégia de crescimento poderia ser sintetizada na ampliação e generalização do consumo de massas”. E Carneiro afirma: “A 
ampliação do consumo de massas fundada na redistribuição de renda seria o fator dinâmico primordial" (2012, p. 774).

Na proposta social-desenvolvimentista é fundamental a ação do Estado, especialmente na questão do investimento, pois este carrega um nível de incerteza que os agentes do mercado nem sempre estão dispostos a enfrentar (MOLO, 2016). Para isso o Estado pode valer-se da política fiscal e da tributação sobre a renda do capital. O papel do Estado também é destacado no sentido de agir para superar o problema estrutural dos países em desenvolvimento, no que tange ao "bloqueio do processo de habilitação", que não é resolvido pelos mecanismos do mercado e pelo crescimento econômico. É preciso que o Estado crie um conjunto consistente de políticas e programas sociais, capazes de viabilizar a inserção produtiva, a distribuição de renda e a inclusão social, que implemente ações internas no sentido de eliminar a pobreza, distribuir e redistribuir renda, viabilizar a inserção produtiva e dinamizar o mercado interno e que realize um conjunto de ações na direção da inserção soberana no cenário internacional, buscando novos espaços para o país e contribuindo para a redução das assimetrias entre as nações (MERCADANTE OLIVA, 2010).

O Programa de Aceleração do Crescimento (PAC) ${ }^{10}$ constitui-se como o programa por excelência desta retomada do desenvolvimentismo, assim como o Plano de Metas foi referência para o desenvolvimentismo clássico. O PAC foi criado pelo Decreto no 6.025, do Presidente da República, de 22 de janeiro de 2007, a fim de acelerar o ritmo de crescimento da economia, aumentar o emprego e a renda, diminuir as desigualdades sociais e regionais e manter os fundamentos macroeconômicos (inflação, consistência fiscal e solidez nas contas externas). O PAC é um programa de desenvolvimento econômico e social que se apoia no planejamento estratégico, na gestão articulada das ações interministeriais, no

9 Remetendo à reflexão de Celso Furtado sobre a abordagem de Amartya Sem, no sentido de contribuir para eliminar as "privações originais" (acesso à terra, à moradia, à educação de qualidade, entre outras), que criam um círculo vicioso que reproduz a pobreza de forma intergeracional (MERCADANTE OLIVA, 2010, p. 18).

10 Informações detalhadas sobre o Programa, bem como os relatórios de suas ações podem ser encontradas em . Lançado inicialmente com uma projeção para o quadriênio 2007-2010, foi reeditado e ampliado nas gestões de Dilma Rousseff (2011 a 2014, como PAC 2 e, em 2015, como PAC 2015-18). Para o PAC 2 os eixos prioritários foram alterados, passando de três para seis: Transportes, Energia, Cidade Melhor, Comunidade Cidadã, Minha Casa Minha Vida e Água e Luz para Todos. Para o PAC 201518, retornou-se aos três eixos presentes no PAC 1: infraestrutura logística, infraestrutura energética e infraestrutura social e urbana. 
fortalecimento da regulação, na gestão de instrumentos financeiros, na parceria entre o setor público e o investidor privado e na articulação entre os entes da federação. Seus programas, projetos e ações estão organizados a partir de três eixos $^{11}$ : infraestrutura logística, infraestrutura energética e infraestrutura social e urbana (BRASIL, 2007).

Concebido para o quadriênio 2007-2010 (PAC 1), ele foi reordenado para o período 2011-2014 (PAC 2) e continua em vigor até o momento (PAC 20152018). O Programa é coordenado no âmbito do Ministério do Planejamento, Orçamento e Gestão, pelo Comitê Gestor do PAC (CGPAC) e possui uma estrutura de gestão ${ }^{12}$ que envolve todos os ministérios implicados, bem como as empresas públicas envolvidas, respondendo diretamente à Presidência da República, no que se refere às ações de governo, e ao Conselho de Desenvolvimento Econômico e Social, no tocante às relações com a sociedade civil.

Os dados do Quadro 1, retirados dos Balanços Quadrimestrais ${ }^{13}$, dão uma noção dos valores envolvidos no PAC, de 2007 a 2016. São utilizados os valores constantes nos balanços finais do PAC 1 (11 ${ }^{\circ}$ balanço, de dezembro de 2010), do PAC 2 (dezembro de 2014) e o $3^{\circ}$ balanço do PAC 2015-2018, de dezembro de 2016, sem atualizações.

O quadro evidencia somas expressivas de investimentos nas diferentes áreas definidas como prioritárias, praticamente dobrando o investimento público e ampliando significativamente o privado, na comparação com períodos anteriores ao lançamento do PAC (BRASIL, 2010, 2014). Destaca-se também que os investimentos no eixo Social e Urbano, no qual se incluem políticas e programas voltados para o desenvolvimento com inclusão social e melhoria das condições de vida da população, ocupam a primeira posição nos três períodos analisados. Os resultados, em termos de indicadores econômicos e sociais, experimentados pelo país, especialmente durante a vigência do PAC 1 e 2, estão diretamente

11 O Eixo da Infraestrutura Logística agrega ações nas áreas de rodovias, ferrovias, portos, hidrovias, marinha mercante e aeroportos. O Eixo da Infraestrutura Energética compreende ações de geração e transmissão de energia elétrica, petróleo, gás natural e combustíveis renováveis. O Eixo de Infraestrutura Social e Urbana agrega ações na área do programa Luz para Todos, na área de Habitação (produção de moradias, assistência técnica, urbanização de favelas, financiamento habitacional - SBPE e Pessoa Física) e saneamento básico.

12 Detalhes sobre a estrutura de gestão podem ser encontrados em . Na página também constam os balanços quadrimestrais, nos quais são elencadas todas as ações, valores envolvidos e andamento das obras. Já foram publicados, desde 2007 até junho de 2017, 26 balanços.

13 Os 26 balanços e os relatórios estão disponíveis em http://www.pac.gov.br/sobre-o-pac/publicacoesnacionais 
associados à proposta de políticas públicas implantadas pelo governo brasileiro. (CALIXTRE, BIANCARELI e CINTRA, 2014). Com o PAC, o governo brasileiro recolocou o Estado como agente decisivo na agenda do desenvolvimento, estabelecendo, com o mercado, um conjunto de relações híbridas e complexas que ainda carecem de maiores estudos e análises (Quadro 1).

Quadro 1 - Valores aplicados no PAC - 2007 a 2016, em reais

\begin{tabular}{|c|c|c|c|}
\hline Informação Básica & PAC 1: 2007-2010 & PAC 2: 2011-2014 & PAC 2015-2018 \\
\hline $\begin{array}{l}\text { Previsão inicial de } \\
\text { investimentos }\end{array}$ & $\begin{array}{l}\text { 503,9 bilhões, } \\
\text { ampliados para } 657 \text { b. }\end{array}$ & 1,59 trilhão & 1,4 trilhão \\
\hline $\begin{array}{l}\text { Investimentos } \\
\text { realizados }\end{array}$ & $\begin{array}{l}619 \text { bilhões } \\
\text { - Estatal: } 202 \mathrm{~b} \text {. } \\
\text { - Privado: } 128 \text { b. } \\
\text { - Orç. Geral União: } \\
55 \text { b. } \\
\text { - Financ. ao setor } \\
\text { público: } 7 \text { b. } \\
\text { - Financ. a pessoa } \\
\text { física: } 216,9 \text { b. } \\
\text { - Contrapartidas } \\
\text { estados e munic,: } \\
\text { 9,3 b. }\end{array}$ & $\begin{array}{l}\text { 1,008 trilhão } \\
\text { - Estatal: } 261,2 \text { b. } \\
\text { - Privado: } 185,7 \text { b. } \\
\text { - Orç. Geral União: } \\
\text { 111,4 b. } \\
\text { - Financ. ao setor } \\
\text { público: } 17,7 \text { b. } \\
\text { - Financ. Habit. : } 341 \text { b. } \\
\text { - Minha Casa Minha } \\
\text { Vida: } 85,5 \text { b. } \\
\text { - Contrapart. estados e } \\
\text { munic.: } 2,5 \text { b. }\end{array}$ & $\begin{array}{l}\text { 386,6 bilhões } \\
\text { - Estatal: } \\
\text { 107,2 b. } \\
\text { - Privado: } 83 \text { b. } \\
\text { - Orç. Geral } \\
\text { União: } 89,3 \text { b. } \\
\text { - } \\
\text { Financiamentos: } \\
\text { 101,9 b. } \\
\text { - Contrap. } \\
\text { estados e munic.: } \\
\text { 5,2 b. }\end{array}$ \\
\hline $\begin{array}{l}\text { Saldo: previsto e } \\
\text { não aplicado }\end{array}$ & 38 bilhões & 582 bilhões & 1, 013 bilhões \\
\hline Ações concluídas & $\begin{array}{l}\text { Até dez. } 2010 \text { - } 444 \text { b. } \\
\text { - Logística: } 65,4 \text { b. } \\
\text { - Energia: } 148,5 \text { b. } \\
\text { - Social e Urbano: } \\
230 \text { b. }\end{array}$ & $\begin{array}{l}\text { Até dez. } 2014 \text { - } \\
\text { 796,4 bilhões. } \\
\text { - Transportes: 66,9 b. } \\
\text { - Energia: } 253,3 \text { b. } \\
\text { - Água e Luz para } \\
\text { Todos: 10,3 b. } \\
\text { - Minha Casa Minha } \\
\text { Vida: 449,7 b. } \\
\text { - Cidade Melhor: 10,7 b. } \\
\text { - Comunidade Cidadã: } \\
\text { 5,5 b. }\end{array}$ & $\begin{array}{l}\text { Até dez. } 2016 \text { - } \\
\text { 172,7 bilhões: } \\
\text { - Logística: } \\
\text { 12,7 b. } \\
\text { - Energia: } \\
\text { 77,4 b. } \\
\text { - Soc. e Urb.: } \\
\text { 82,6 b. }\end{array}$ \\
\hline
\end{tabular}

Fonte: BRASIL (2010, 2014 e 2016) - organizado pelos autores.

As críticas ao PAC também são intensas e recorrentes, tanto em seus fundamentos macroeconômicos que não rompem com os princípios neoliberais (SANTOS et al., 2010), quanto na sua concepção, nos programas prioritários, investimentos realizados e resultados obtidos (RODRIGUES; SALVADOR, 
2011). O PAC surgiu como uma promessa de retorno do Estado como indutor do crescimento econômico de forma planejada, porém, apesar da propaganda desenvolvimentista, apresentou-se como um programa pontual, com recursos limitados, com execução orçamentária bem abaixo do previsto, com baixa efetividade como multiplicador de investimentos privados na economia, servindo para a manutenção da política econômica vigente que privilegia o capital (RODRIGUES; SALVADOR, 2011). As desonerações tributárias e as medidas institucionais adotadas no âmbito do PAC acabaram contribuindo para a apropriação indireta de recursos do fundo público que seriam remetidos ao financiamento de políticas sociais, especialmente a educação e a seguridade social.

\section{CONSIDERAÇÕES FINAIS}

O contexto desenvolvimentista brasileiro tem sua primeira ocorrência a partir da crise do modelo agrário exportador e da necessidade de construir alternativas capazes de enfrentar os problemas socioeconômicos e político-culturais de uma sociedade marcada por históricas desigualdades. Tal ocorrência se efetiva ao longo das décadas de 1930 a 1950, em seu substrato econômico e ideológico, com a presença de concepções do positivismo, do keynesianismo, do estruturalismo cepalino e das críticas ao liberalismo e ao socialismo. Apresenta, como núcleo central da proposta, o protagonismo do Estado na concepção, no planejamento e na execução da política econômica, fundada no desenvolvimento da indústria e no fortalecimento do mercado interno, com vistas a implantar um projeto nacional na direção da superação dos problemas econômicos e sociais, nos marcos do sistema capitalista.

O Plano de Metas representou o momento áureo do desenvolvimentismo clássico brasileiro, pois viabilizou a implantação de um projeto identificado com a ideologia desenvolvimentista dominante no período que propalava a necessária modernização das atividades produtivas, das relações sociais e das instituições como fatores essenciais para inserir o Brasil na dinâmica das modernas nações capitalistas. A ação incisiva do governo JK no sentido de garantir uma hegemonia política consistente e capaz de implantar medidas de promoção do desenvolvimento da indústria, modernização da infraestrutura produtiva, integração das diferentes regiões em uma economia nacional e articulação entre 
o capital nacional e o internacional, fez com que o Brasil desse passos significativos na transição de uma economia agrária exportadora para uma economia urbano-industrial, ainda que inserida, de forma dependente e associada, no circuito do capitalismo internacional.

Sem dúvidas que, independentemente das disputas político-partidárias e ideológicas, tradicionalmente muito frequentes nos estamentos de poder brasileiro, os resultados do plano de metas quanto ao desenvolvimento econômico transformaram as relações societárias e a cena urbana e rural do País, bem como o alcance de sua inserção internacional.

A retomada de discussões, debates e consequentes formulações de políticas de corte desenvolvimentista ocorre na primeira década do século XXI. Esses fóruns, efetivamente, se propositam na esteira da crise das formulações de políticas econômicas e sociais implantadas com base no ideário neoliberal na última década do século XX. Desses fóruns, emergem dois grupos que divergem na formulação das políticas, mas não em seu conteúdo. Identifica-se, neste ponto, a tradicional díade brasileira: situação e oposição. Sendo que os teóricos adeptos a situação entende a formulação de políticas na perspectiva do social desenvolvimentismo, enquanto que os identificados com a oposição contra-argumentam com a concepção de políticas que fundamentam a lógica novo-desenvolvimentismo. Assim, os teóricos de oposição mantêm a centralidade no econômico, afirmando que somente será possível pensar em um projeto nacional capaz de realizar as mudanças estruturais necessárias, manter o crescimento sustentado da economia a taxas elevadas e viabilizar a disseminação da riqueza pelos diferentes estratos da população, a partir de um Estado e um mercado fortes e de uma política macroeconômica adequada. Já os teóricos identificados com a situação trabalham com a ideia do social como eixo do desenvolvimento, efetivado pela ação incisiva do Estado na regulação do mercado, na condução dos investimentos e na implantação de política fiscal e tributária de modo a ativar um círculo virtuoso do crescimento e possibilitar a implantação de conjunto consistente de políticas e programas sociais na direção da proteção, da promoção e da infraestrutura, capazes de viabilizar a inserção produtiva, a distribuição de renda e a inclusão social. O PAC representou o programa de referência desta retomada do desenvolvimentismo, na medida em que recolocou o Estado como agente indutor do desenvolvimento, em diálogo com o mercado e a 
sociedade civil, e apresentou resultados expressivos em termos de indicadores sociais e econômicos.

Resta evidente, no entanto, que as propostas desenvolvimentistas, por mais que incluam preocupações sociais, possuem centralidade no econômico e se mantêm afetas aos limites do capitalismo. As ações do Estado, especialmente no manejo das políticas públicas, são sensíveis ao arranjo de forças hegemônicas no contexto histórico específico e acabam por contribuir para o processo de reprodução do capital.

\section{REFERÊNCIAS}

BASTOS, Pedro P. Z. A economia política do novo-desenvolvimentismo e do social desenvolvimentismo. Economia e Sociedade, Campinas, v. 21, Número Especial, p. 779-810, dez. 2012.

BIELSCHOWSKY, Ricardo. O Desenvolvimentismo: do pós-guerra até meados dos anos 1960. In: BIELSCHOWSKY, Ricardo et al. O desenvolvimento econômico brasileiro e a Caixa: palestras. Rio de Janeiro: Caixa Econômica Federal, 2011, p. 15-22.

BRASIL. Programa de Metas do Presidente Juscelino Kubitschek: estado do plano de desenvolvimento econômico em 30 de junho de 1958. Rio de Janeiro: Presidência da República, 1958.

BRASIL. Balanço PAC $-1^{\circ}$ ano. O crescimento passa por aqui. Brasília: Ministério do Planejamento, 2007.

BRASIL. Balanço PAC 4 anos 2007-2010. Brasília: Ministério do Planejamento, 2010.

BRASIL. PAC - $3^{\circ}$ Balanço 2015-2018. Brasília: Ministério do Planejamento, Desenvolvimento e Gestão, 2016.

BRESSER PEREIRA, Luiz C. Teoria novo-desenvolvimentista: uma síntese. Cadernos do Desenvolvimento, Rio de Janeiro, v. 11, n. 19, p. 145-165, juldez. 2016.

CALIXTRE, André B.; BIANCARELLI, André M.; CINTRA, Marcos A. M. (Org.). Presente e futuro do desenvolvimento brasileiro. Brasília: IPEA, 2014, p. 29-78. 
CARDOSO JUNIOR, José C.; NAVARRO, Cláudio A. O planejamento governamental no Brasil e a experiência recente (2007 a 2014) do Programa de Aceleração do Crescimento (PAC). Brasília; Rio de Janeiro: IPEA, 2016.

CARDOSO, Miriam L. Ideologia do desenvolvimento - Brasil: JK-JQ. Rio de Janeiro: Paz e Terra, 1977.

CARNEIRO, Ricardo de M. Velhos e novos desenvolvimentismos. Economia e Sociedade, Campinas, v. 21, Número Especial, p. 749-778, dez. 2012.

COSTA, Everaldo B. da; STEINKE, Valdir A. Brasília meta-síntese do poder no controle e articulação do território nacional. Scripta Nova. Brasília, $\mathrm{n}^{\circ}$ 493(44), p. 01-27, 2014.

DIAS, José L. de M. O BNDE e o plano de metas - 1956/61. In: BNDES. O BNDES e o plano de metas. Rio de Janeiro: BNDES, 1996, p. 31-153.

FONSECA, Pedro D. C. Desenvolvimentismo: a construção do conceito. In: CALIXTRE, André B.; BIANCARELLI, André M.; CINTRA, Marcos A. M. (Org.). Presente e futuro do desenvolvimento brasileiro. Brasília: IPEA, 2014, p. 29-78.

GRAMSCI, Antônio. Maquiavel, a política e o Estado moderno. Tradução de Luiz Mário Gazzaneo. Rio de Janeiro: Civilização Brasileira, 1968.

JARDIM, Maria C.; SILVA, Márcio R. Programa de Aceleração do Crescimento (PAC): neodesenvolvimentismo? São Paulo: UNESP, 2015.

LAFER, Celso. JK e o programa de metas, 1956-1961: processo de planejamento e sistema político no Brasil. Rio de Janeiro: FGV, 2002.

LESSA, Carlos. 15 Anos de Política Econômica. 3.ed. São Paulo: Brasiliense, 1982.

MENDONÇA, Sônia R. de. Estado e Políticas públicas: considerações político-conceituais. Outros Tempos, São Luís (MA), vol. 1 esp., 2007, p. 1-12. MERCADANTE OLIVA, Aloizio. As bases do novo desenvolvimentismo no Brasil: análise do governo Lula (2003-2010). Tese (Doutorado em Economia), Instituto de Economia/UNICAMP, Campinas, 2010.

MOLO, Maria de L. R. Desenvolvimentismos, inclusão social e papel do Estado. Cadernos do Desenvolvimento, Rio de Janeiro, v. 11, n. 19, p. 131143, jul./dez. 2016.

NETTO, José P. Crise do capital e consequências societárias. Serviço Social e Sociedade, São Paulo, n. 111, p. 413-429, jul/set. 2012.

PFEIFER, Mariana. O "social" no interior do projeto neodesenvolvimentista. Serviço Social e Sociedade, São Paulo, n. 120, p. 746-766, out./dez. 2014. 
RABELO, Ricardo F. Plano de Metas e consolidação do capitalismo industrial no Brasil. E \& G Economia e Gestão, Belo Horizonte, v. 2 e 3, n. 4 e 5, p. 44 55, dez. 2002/jul. 2003.

RODRIGUES, Taíla A.; SALVADOR, Evilasio. As implicações do Programa de Aceleração do Crescimento (PAC) nas Políticas Sociais. SER Social, Brasília, v. 13, n. 28, p. 129-156, jan./jun. 2011.

ROTTA, Edemar. Desenvolvimento regional e políticas sociais no noroeste do estado do Rio Grande do Sul. Tese (Doutorado em Serviço Social), PPGSS/PUCRS, Porto Alegre, 2007.

SANTOS, Cleusa et al. PAC: uma orientação neoliberal para as políticas sociais - gestão dos direitos ou dos negócios do social? Ser Social, Brasília, v. 12, n. 26, p. 116-46, jan./jun. 2010.

SICSÚ, João; PAULA, Luiz F. de; MICHEL, Renaut. Por que novodesenvolvimentismo? Revista de Economia Política, vol. 27, no 4 (108), p. 507-524, out./dez. 2007.

SILVA, Maria E. B. R. O Estado em Marx e a teoria ampliada do Estado em Gramsci. 2015. Disponível em: https://www.unicamp.br/cemarx/ANAIS\%20 IV\%20COLOQUIO/comunica\%E7\%F5es/GT2/gt2m5c5.pdf. Acesso em: 23 maio 2017.

SILVA, Ricardo. Planejamento econômico e crise política: do esgotamento do plano de desenvolvimento ao malogro dos programas de estabilização. Revista de Sociologia e Política, Curitiba, n. 14, p. 77-101, jun. 2000.

SOUZA, Celina. Políticas públicas: uma revisão de literatura. Sociologias, Porto Alegre, ano 8, n. 16, p. 20-45, jul/dez. 2006. 